\title{
Mosquito species (Diptera: culicidae) collected after tropical storm cristobal in Merida, Yucatan, South-east Mexico
}

\author{
Juan Navarrete-Carballo ${ }^{1}$ Wilberth Bibiano-Marín ${ }^{1,2} \cdot$ Jorge Palacio-Vargas $^{2} \cdot$ Herón Huerta-Jiménez $^{3}$. \\ Marco Torres-Castro ${ }^{4} \cdot$ Carlos Arisqueta-Chable $^{1} \cdot$ Anuar Medina-Barreiro $^{1} \cdot$ Henry Puerta-Guardo ${ }^{1}$. \\ Azael Che-Mendoza ${ }^{1} \cdot$ Abdiel Martin-Park $^{1}$ (1) Pablo Manrique-Saide ${ }^{1}$
}

Received: 15 February 2021 / Accepted: 18 October 2021 / Published online: 29 October 2021

(c) African Association of Insect Scientists 2021

\begin{abstract}
After the tropical storm Cristobal, we performed special adult entomological collections in the peri-domicile of 35 houses from 25 neighborhoods of Mérida, Yucatan, Mexico in response to complaints from the community about an increased nuisance due to an abundance of mosquitoes. A total of 1,275 specimens from four genera and 13 species were collected: Aedes taeniorhynchus (92\%), Culex quinquefasciatus (72\%), Aedes aegypti (72\%), Psorophora mexicana (36\%), Psorophora cyanescens (32\%), Aedes scapularis (24\%), Culex nigripalpus (24\%), Aedes albopictus (8\%), Psorophora ferox (4\%), Haemagogus equinus (4\%), Aedes trivittatus (4\%), Culex coronator (4\%), Culex iolambdis (4\%). From these collections, the increased mosquito nuisance was mainly the result of invasive species such as Aedes taeniorhynchus and Psorophora. City wide, vehicle mounted ULV spraying was performed by the MoH and the municipality of Merida to control adult mosquito populations. We report Culex iolambdis for the first time in Merida and Psorophora mexicana for the state of Yucatan.
\end{abstract}

Keywords Mosquitoes $\cdot$ Surveillance $\cdot$ Tropical storm $\cdot$ Mexico

From the 1st to 6th June of 2020, the tropical storm Cristobal moved across the Yucatan Peninsula in South-East Mexico. Characterized by its large size, winds and associated heavy rainfall, (with a record $623.3 \mathrm{~mm}$ ) it caused widespread damage mainly due to flooding in the Mexican state of Yucatan, including the capital city of Merida (CONAGUA 2020). Following its course there were many reports from

Juan Navarrete-Carballo and Abdiel Martin-Park contributed equally to this manuscript.

Abdiel Martin-Park

ampark27@gmail.com

1 Universidad Autónoma de Yucatán, Unidad Colaborativa Para Bioensayos Entomológicos, Campus de Ciencias Biológicas y Agropecuarias, Mérida, Yucatán, C.P 97315, México

2 Servicios de Salud de Yucatán, Mérida, Yucatán, C.P 97000, México

3 Lomas de Plateros, Instituto de Diagnóstico Y Referencia Epidemiológicos (InDRE), Secretaría de Salud Francisco de P. Miranda 177, Ciudad de México, México

4 Centro de Investigaciones Regionales Dr, Hideyo NoguchiUniversidad Autónoma de Yucatán, Mérida, México the residents of Merida which contained complaints about an increased nuisance due to an abundance of "giant black mosquitoes", that were perceivably different from the common species (v.g. Aedes or Culex spp.), which had invaded neighborhoods and housing units in the East and West of the city with an associated concern for the potential spread of arboviruses (TYT 2020a, b).

Because of the COVID-19 contingency, non-intrusive rapid activities of surveillance and control of invasive nuisance species were implemented as part of response by the local Ministry of Health $(\mathrm{MoH})$ to the reports of the community. Mosquito surveillance in urban areas is an integral part of the entomological surveillance protocol of the $\mathrm{MoH}$ of Yucatan and in many tropical cities of Mexico (DOF 2015). Ovitrapping for Aedes species, mainly Aedes aegypti is a systematic method (CENAPRECE 2015a) now set as a network with 5,183 ovitraps (dark containers with water and a rough surface covered with oviposition pieces of paper) distributed throughout the city (Gonzalez-Olvera et al. 2021); however, this method only detects container breeding mosquito species. Adult collections with portable electric aspirators are also performed across the city for adult mosquito 
surveillance, but only in 2-3 cross sectional surveys every year since 2013 (CENAPRECE 2015b).

Merida city capital of Yucatan state has a warm subhumid climate (Aw0 (x ') (i') g), with an average annual temperature of $28^{\circ} \mathrm{C}$; the minimum and maximum is $16^{\circ} \mathrm{C}$ and $36{ }^{\circ} \mathrm{C}$ in January and May, respectively. The rainfall average is $1342.9 \mathrm{~mm}$ per year, with the rainy season occurring from May to November (García 2004). Special adult entomological collections were carried out from the 9th to 30th of June 2020 (three days after the storm finished) in the peri-domicile of 35 houses from 25 neighborhoods of Mérida city (Fig. 1). Staff of the Collaborative Unit for Entomological Bioassays of the Autonomous University of Yucatán (UCBE-UADY) and the local MoH, carried out 10-min collections per house of adult mosquitoes attracted to humans between 8:00 and 14:00 $\mathrm{h}$ with Prokopack aspirators (Vazquez-Prokopec et al. 2009). Collected specimens were preserved in containers and transferred to UCBE-UADY for sacrifice by freezing $\left(-20^{\circ} \mathrm{C}\right)$ and were later identified using specialized keys (Darsie and Ward 2005; Harrison et al. 2008). Sample of the specimens were sent to the National Entomology Laboratory of Instituto de Diagnóstico y Referencia Epidemiológicos (InDRE) of the Mexican Ministry of Health for species confirmation and were deposited in the InDRE Collection of Arthropods with Medical Importance (CAIM).

In total, 1,275 specimens of mosquito from 4 genera and 13 species were collected: Aedes taeniorhynchus (92\%), Culex quinquefasciatus (72\%), Aedes aegypti (72\%), Psorophora mexicana (36\%), Psorophora cyanescens (32\%), Aedes scapularis (24\%), Culex nigripalpus (24\%), Aedes albopictus (8\%), Psorophora ferox (4\%), Haemagogus equinus (4\%), Aedes trivittatus (4\%), Culex coronator (4\%), Culex iolambdis (4\%) (Table 1). The collection with Prokopack aspirators while being attracted to the collectors suggests that they are anthropophilic to a greater or lesser
Fig. 1 Species of mosquitoes collected after the tropical storm Cristobal (June 2020) with Prokopack aspirators in the peridomicile of houses (dots) and various neighborhoods (shaded areas) of the city of Merida, Yucatan, Mexico

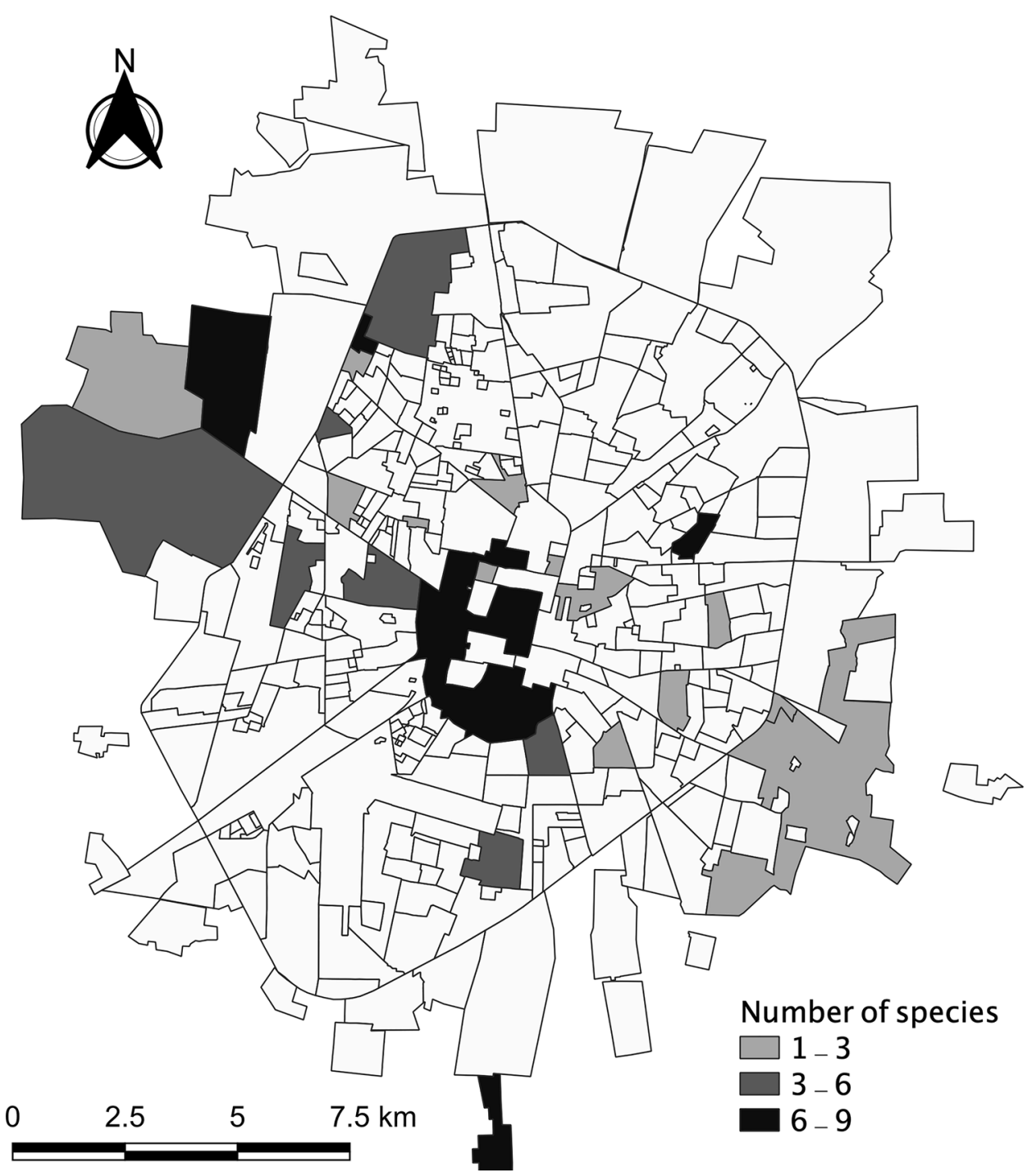




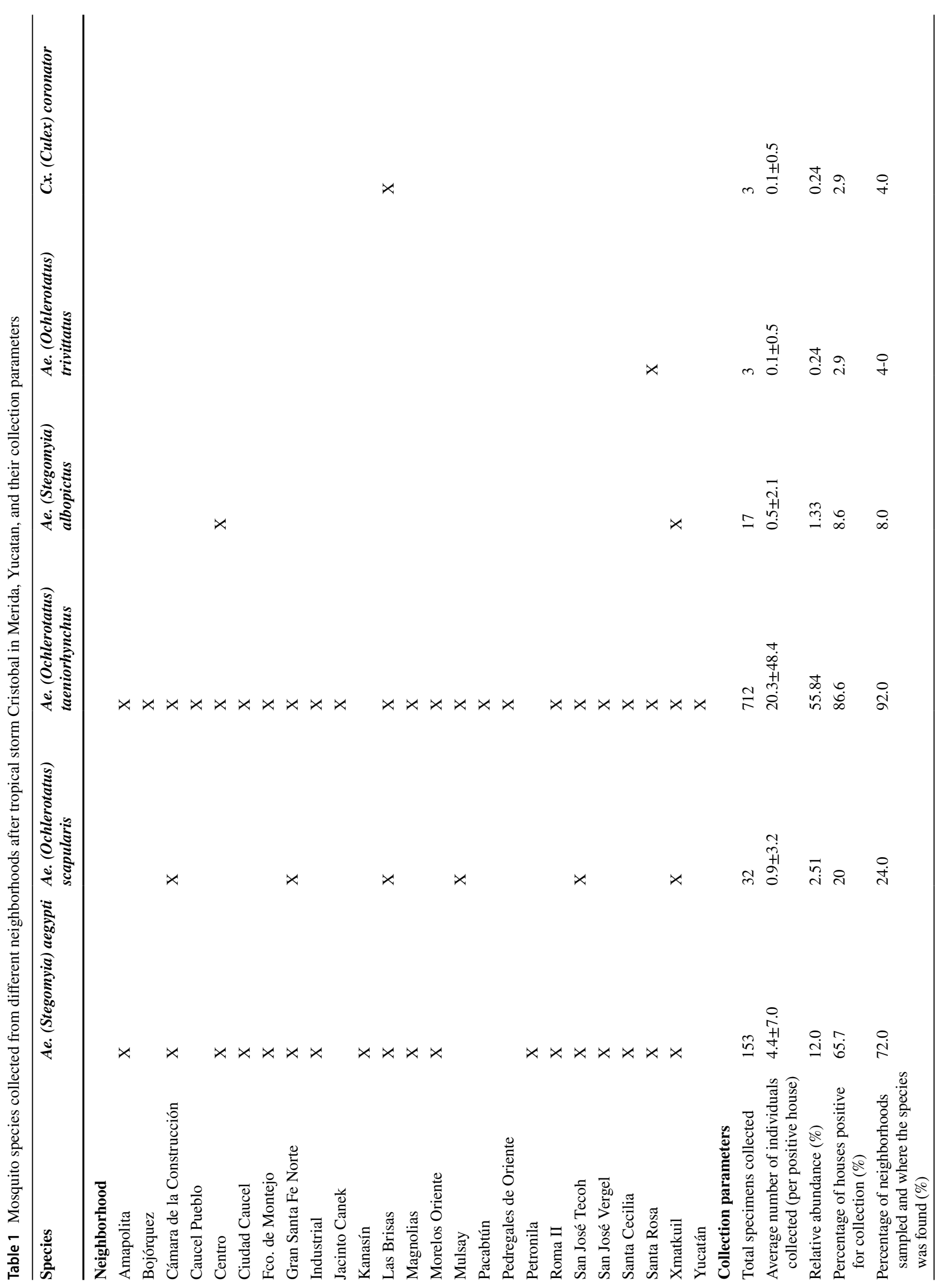


2010

International Journal of Tropical Insect Science (2022) 42:2007-2012

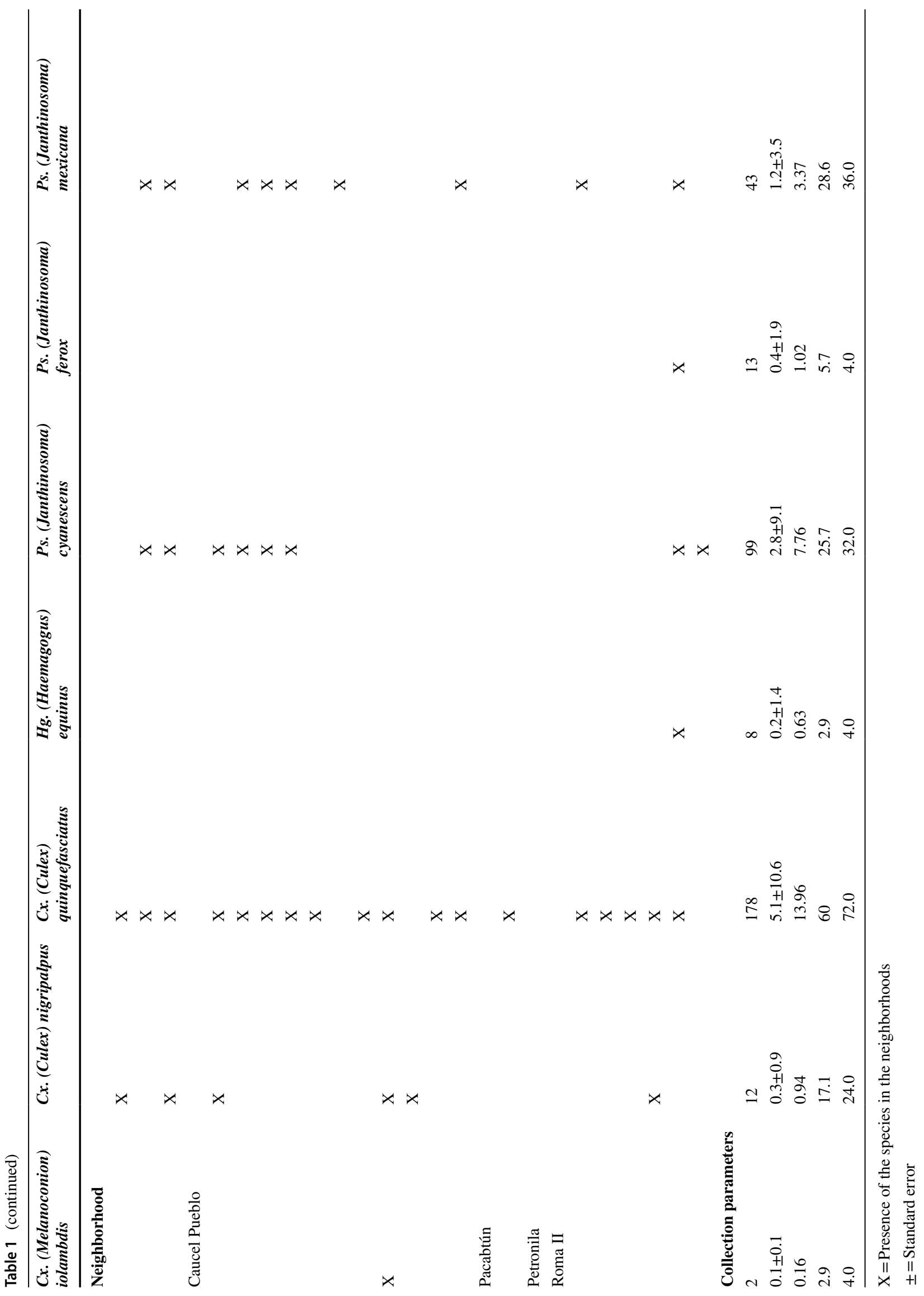

Springer 
degree. Most of the species have been previously reported in Merida, from larvae growing in containers predominantly in the peri-domicile (backyard). Reports come largely from larval surveys made by the $\mathrm{MoH}$ and research projects (Najera-Vazquez et al. 2004; Zapata-Peniche et al. 2007; Manrique-Saide and Zapata-Peniche 2010; Manrique-Saide et al. 2010; Baak-Baak et al. 2016). In this context, one of the most important factors which contribute with mosquito diversity in Merida is the wide availability and productivity of artificial and natural breeding sites (Manrique-Saide and Zapata-Peniche 2010), which include bottles, bath, cooking and washing utensils, pet animal drinking dishes, swimming pool, flowerpots, small plastic rubbish, large tanks, tires, natural holes (rocks, trees), cans, laundry tubes, discarded appliances, stormwater drains/catch basins and miscellaneous objects (Zapata-Peniche et al. 2007; Manrique-Saide et al. 2008).

The most abundant species collected was Aedes (Ochlerotatus) taeniorhynchus, which represented 56\% of the collected specimens, with a wide distribution in the houses (86.6\%) and neighborhoods (92\%) sampled (Table 1). This species, known as the black salt marsh mosquito, has been reported as a predominant species after storms (Morrow et al. 2008). In Yucatan, it is very common in the coastal areas (Manrique-Saide et al. 2010) and frequently invades Merida (which is $30 \mathrm{~km}$ from the coast) in large numbers after storm winds, heavy rains, and flooding events (Manrique-Saide and Zapata-Peniche 2010). The other most common and widely distributed species collected were Culex quinquefasciatus and Aedes (Stegomyia) aegypti (Table 1), which were collected in lower numbers than Ae. taeniorhynchus but were found in 60-70\% of the houses and neighborhoods sampled. Both species, well adapted to the human environment and breed in peridomiciliary man-made breeding sites (Zapata-Peniche et al. 2007; Manrique-Saide et al. 2008), are common in Merida and other human settlements of Yucatan (Najera-Vazquez et al. 2004; Baak-Baak et al. 2016).

Two other species, Aedes (Ochlerotatus) scapularis (Rondani) and Culex (Culex) nigripalpus (Theobald), were collected in low numbers but found in around $30 \%$ of the neighborhoods. These species have been also previously reported from Merida, with low numbers and breeding in outdoor containers (Zapata-Peniche et al. 2007; Baak-Baak et al. 2016). The remaining species of the genera Culex and Aedes, including Ae. (Stegomyia) albopictus, have been previously reported breeding in low numbers in Merida and suburban areas (Najera-Vazquez et al. 2004; Zapata-Peniche et al. 2007; Manrique-Saide and Zapata-Peniche 2010; Contreras-Perera et al. 2019; Gonzalez-Olvera et al. 2021). This is consistent with previous surveys in Merida, where most of the mosquito species reported were found in a variety of artificial and natural breeding sites. Especially, Ae. aegypti, Cx. thriambus,
$C x$. quinquefasciatus, and Cx. coronator were observed in all categories of breeding sites described above (ManriqueSaide et al. 2008; Manrique-Saide and Zapata-Peniche 2010; Baak-Baak et al. 2016).

Some of the reports in the media and on social media described large mosquitos similar to Psorophora species (TYT 2020a, b). Indeed, three Psorophora species: Ps. (Janthinosoma) cyanescens (Coquillett), Ps. (Janthinosoma) ferox (von Humboldt) and Ps. (Janthinosoma) mexicana, were collected from houses at Merida. Ps. cyanescens were collected in larger numbers than the others, but both $P S$. cyanescens and Ps. mexicana were collected in around 30\% of the neighborhoods sampled. These species are not commonly found, much less with such abundance and distribution, in the residential urban area of Merida. In fact, we report the species Ps. mexicana for the first time for the state of Yucatan, previously this species was reported in the locality of Lerma and the south of Campeche State in the Yucatan Peninsula (Heinemann and Belkin 1977). Cx. iolambdis represent new record for the city of Merida, this species is common in the coast and flooded areas of Yucatan. And was reported in the municipalities of Dzemul and Progreso in Yucatan State (Baak-Baak et al. 2016; Navarrete-Carballo et al. 2021). We argue that local invasion of these species was because of the storm. Now sum 30 reported species for Merida (Najera-Vázquez et al. 2004; Zapata-Peniche et al. 2007; Manrique-Saide and Zapata-Peniche 2010; Baak-Baak et al. 2016). Ps. mexicana can be distinguished from other related species by its hind tarsomere 4 entirely dark scaled, rarely with pale scales at base and its 5 tarsomere entirely or rarely partially pale scaled. The larva and males of $P S$. mexicana are unknown (Darsie and Ward 2005; Harrison et al. 2008).

Similar events occurred in St. John's County, FL (comparable climate conditions as Yucatan) from Hurricane Matthew and Irma (2016 and 2017 respectively). The flooding triggered mosquito population outbreaks after 10 and 9 days (2nd peak event after a month), respectively (with similar species composition as reported in this study). In response of the outbreaks, the control services used intensively and extensively both ground (ULV, larvicides) and aerial applications for control (Weaver et al. 2020).

From these results, it is reported that the increase in mosquitoes was due to invasive species such as Ae. taeniorhynchus and Psorophora species (TYT 2020a, b). City wide, vehicle mounted ULV spraying was performed by the $\mathrm{MoH}$ and the municipality of Merida to control adult mosquito populations. An intensive campaign to eliminate mosquito breeding sites with "Descacharrización" (Barrera et al. 2015) complemented by the distribution of larvicide was also performed as part of the protocol to control Ae. aegypti in emergency situations to prevent the risk of dengue, chikungunya and Zika transmissions. 
Research funding was provided by the Canadian Institutes of Health Research (CIHR) and The International Development Research Centre (IDRC) (Preventing Zika disease with novel vector control approaches Project 108412 and Enabling Business and Technologies to Contribute to the Control of Mosquito-Borne Diseases in Latin America Project 109071-002) and by Fondo Mixto CONACyT (Mexico)-Gobierno del Estado de Yucatán (Project YUC2017-03-01-556). Abdiel Martin-Park is supported by the Catedras-CONACYT program. Special thanks to Suzanna Shugert for grammatical corrections.

\section{Declarations}

Competing interests We declare no conflict of interest.

\section{References}

Baak-Baak CM, Cigarroa-Toledo N, Anana-Giardia R, Chi WA, Chan JA, Machain-Williams C, Torres-Chable OM, Ortega-Morales A, MooLlanes DA, Elizondo-Quiroga A, García Rejón JE (2016) Mosquito fauna associated with Aedes aegypti (Diptera: Culicidae) in Yucatán State of southeastern Mexico, and checklist with new records. Fla Entomol 99:703-709

Barrera-Pérez MA, Pavía-Ruz N, Mendoza-Mézquita JE, Torres-Arcila N, Hernández-Hernández R, Castro-Gamboa F, Geded-Moreno E, Cohuo-Rodríguez A, Medina-Barreiro A, Koyoc-Cardeña E, Gómez-Dantés H, Kroeger A, Vázquez-Prokopec G, ManriqueSaide P (2005) Control of Aedes aegypti breeding sites with the program Recicla por tu bienestar in Mérida, México. Salud Publ Mex 57:201-210

Centro Nacional de Programas Preventivos y Control de Enfermedades [CENAPRECE] (2015a) Guía metodológica para vigilancia entomológica con ovitrampas. https:// www. gob. mx/cms/uploads/attachment/file/43289/ GuiaMetodologicaVigilanciaEntomologicaOvitrampas.pdf. Accessed 10 July 2020

Centro Nacional de Programas Preventivos y Control de Enfermedades [CENAPRECE] (2015b) Guía metodológica para vigilancia entomovirológica. https://www.gob.mx/cms/uploads/attachment/file/ 43289/GuiaMetodologicaVigilanciaEntomologicaOvitrampas.pdf. Accessed 10 July 2020

Comisión Nacional del Agua [CONAGUA] (2020) Lluvias asociadas a ciclones tropicales. Ciudad de México. https://smn.conagua.gob. $\mathrm{mx} / \mathrm{es} /$ ciclones-tropicales/lluvias-asociadas-a-ciclones-tropicales. Accessed 12 July 2020

Contreras-Perera YJ, Briceño-Méndez M, Flores-Suárez AE, ManriqueSaide P, Palacio-Vargas JA, Huerta-Jiménez H, Martin-Park A (2019) New record of Aedes albopictus in a suburban area of Merida, Yucatan, Mexico. J Am Mosq Control Assoc 35:210-213

Darsie Jr RF, Ward RA (2005) Identification and geographical distribution of the mosquitoes of North America, North of Mexico. Walter Reed Army Institute of Research, Washington D.C pp 17-97

Diario Oficial de la Federación [DOF] (2015) Norma Oficial Mexicana NOM-032-SSA2-2014, Para la vigilancia epidemiológica, promoción, prevención y control de las enfermedades transmitidas por vectores. México, DF. Secretaría de Gobernación. http://www.dof. gob.mx/nota_detalle.php?codigo $=5389045 \&$ fecha $=16 / 04 / 2015$. Accessed 12 July 2020
García E (2004) Modificaciones al sistema de clasificación climática de Köppen. Serie Libros $N^{\circ} 6$, Instituto de Geografía, Universidad Nacional Autónoma de México, pp 90

González-Olvera G, Morales-Rodríguez M, Bibiano-Marín W, PalacioVargas J, Contreras-Perera Y, Martín-Park A, Che-Mendoza A, Torres-Castro M, Correa-Morales F, Huerta-Jiménez H, Mis-Ávila P, Vázquez-Prokopec G, Manrique-Saide P (2021) Detección de Aedes (Stegomyia) albopictus (Skuse) en ovitrampas de la ciudad de Mérida, México. Biomed 41:153-160

Heinemann SJ, Belkin JN (1977) Collection records of the project Mosquitoes of Middle America 9. Mexico (MEX, MF, MT, MX). Mosq Syst 9:481-535

Harrison BA, Varnado W, Whitt PB, Goddard J (2008) New diagnostic characters for females of Psorophora (Janthinosoma) species in the United States, with notes on Psorophora mexicana (Bellardi) (Diptera: Culicidae). J Vector Ecol 33:232-237

Manrique-Saide P, Davies CR, Coleman P, Rebollar-Tellez E, CheMedoza A, Dzul-Manzanilla F, Zapata-Peniche A (2008) Pupal surveys for Aedes aegypti surveillance and potential targeted control in residential areas of Merida, Mexico. J Am Mosq Control Assoc 24:289-298

Manrique-Saide P, Zapata-Peniche A (2010) Mosquitos de Mérida. In: Durán R, Méndez M (eds) Biodiversidad y Desarrollo Humano en Yucatán. Mérida, México: CICY, PPD-FMAM, CONABIO, SEDUMA. p 233

Manrique-Saide P, Escobedo-Ortegón J, Bolio-González M, Sauri-Arceo C, Dzib-Florez S, Guillermo-May G, Ceh-Pavía E, Lenhart A (2010) Incrimination of the mosquito Aedes taeniorhynchus, as the primary vector of heartworm, Dirofilaria immitis, in coastal Yucatan, Mexico. Med Vet Entomol 24:456-460

Morrow MG, Johnson RN, Polanco J, Claborn DM (2008) Mosquito vector abundance immediately before and after Tropical Storms Alma and Arthur, northern Belize. Rev Panam Salud Públ 28:19-24

Nájera-Vázquez R, Dzul F, Sabido M, Tun-Ku E, Manrique-Saide P (2004) New distribution records of mosquitoes (Diptera: Culicidae) for Yucatán, México. Entomol News 115:181-190

Navarrete- Carballo J, Chan-Espinoza D, Huerta H, Trujillo-Peña E, López-Platas J, Vivas-Pérez D, Damasco Córdova K, Medina Barreiro A, Delfín González H, Manrique-Saide P, Martin-Park A (2021) Diversity of Culicidae and Tabanidae (Diptera) and new record of Uranotaenia sapphirina from the archaeological site of X'cambó, Yucatan, Mexico. Int J Trop Insect Sci 41:1355-1363

The Yucatan Times [TYT] (2020a) Giant black mosquito arrives in Mérida, Yucatán, México. https://www.theyucatantimes.com/2020/ 06/giant-black-mosquito-arrives-in-merida/. Accessed 12 June 2020

The Yucatan Times [TYT] (2020b) An intensive campaign to eliminate mosquito breeding sites in Mérida this weekend. https:// www.theyucatantimes.com/2020/06/an-intensive-campaign-toeliminate-mosquito-breeding-sites-in-merida-this-weekend/. Accessed 12 June 2020

Vazquez-Prokopec GM, Galvin WA, Kelly R, Kitron U (2009) A new, cost-effective, battery-powered aspirator for adult mosquito collections. J Med Entomol 46:1256-1259

Weaver JR, Xue R, Gaines MK (2020) Population outbreaks of mosquitoes after hurricanes Matthew and Irma and the control efforts in St. Johns County, Northeastern Florida. J Am Mosq Control Assoc 36:28-34

Zapata-Peniche A, Manrique-Saide PC, Rebollar- Téllez EA, CheMendoza A, Dzul-Manzanilla F (2007) Identificación de larvas de mosquitos (Diptera: Culicidae) de Mérida, Yucatán, México y sus principales criaderos. Biomed 18:3-17

Publisher's Note Springer Nature remains neutral with regard to jurisdictional claims in published maps and institutional affiliations. 